\title{
DIREITO, TÉCNICA E DISTOPIA: UMA LEITURA CRÍTICA
}

\author{
Andityas Soares de Moura Costa Matos
}

LAW, TECHNIQUE AND DYSTOPIA: A CRITICAL APROACH

\section{RESUMO}

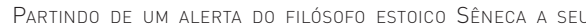
DISCÍPULO LUCílIO, O PRESENTE ARTIGO PRETENDE REFLETIR SOBRE O FENÔMENO DA DESUMANIZAÇÃO DAS ORDENS JURÍDICAS, DESCREVENDO AS SUAS CAUSAS E AS CONSEQUÊNCIAS QUE PODEM ADVIR DO APROFUNDAMENTO DESSE PROCESSO. EM PRIMEIRO LUGAR, ANALISA-SE A CHAMADA TECNICIZAÇÃO DO DIREITO, DIFERENCIANDO-A DO FORMALISMO JURÍDICO PROPUGNADO PELO JUSPOSITIVISMO. DENTRE OS VÁRIOS FATORES DE DESUMANIZAC̣ÃO DOS ORDENAMENTOS JURÍDICOS, SUBLINHA-SE A UNIDIMENSIONALIZAÇĀO DAS SOCIEDADES Pós-INDUSTRIAIS. POR FIM, DESCREVE-SE O DIREITO ENQUANTO DISTOPIA, APONTANDO ALGUMAS POSSÍvEIS ALTERNATIVAS PARA A RECONSTRUÇÃO DE UM DISCURSO JUSFILOSÓFICO CONTEMPORÂNEO SOBRE A JUSTICCA, DE MANEIRA A SUPERAR AS FORMAS DE CONVIVIIO SOCIAL HOJE IMPOSTAS QUE APRESENTAM CARACTERÍSTICAS PARTICULARMENTE AUTORITÁRIAS E PERVERSAS.

\section{PALAVRAS-CHAVE}

JUSPOSITIVISMO; TECNICIZAÇÃO; UNIDIMENSIONALIZAÇÃO; UtOPIA E DISTOPIA; DIREITO E LITERATURA.

\begin{abstract}
REFERRING BACK TO A WARNING FROM THE STOIC PHILOSOPHER SENECA TO HIS FOLLOWER LUCILIUS (EP. XCV, 53), THIS PAPER CONTAINS CONSIDERATIONS ON BOTH THE PHENOMENON OF A DE-HUMANIZING PROCESS THAT HAS DEFACED THE LEGAL SYSTEMS AND POINTS OUT THE RESPECTIVE CAUSES AND LIKELY CONSEQUENCES ANY INTENSIFICATION OF SUCH A PROCESS MAY HAVE ON SAID LEGAL SYSTEMS. THE SO-CALLED TECHNICIZATION OF THE SCIENCE OF LAW, FOR INSTANCE, IS REVIEWED AND CONTRASTED WITH THE LEGAL FORMALISM ADVOCATED BY THE JUSPOSITIVISM. MOREOVER, AMONG OTHER MULTIPLE DE-HUMANIZING FACTORS AFFECTING THE LEGAL SYSTEM, THE UNIDIMENSIONALIZATION OF POST-INDUSTRIAL SOCIETIES HAS ALSO BEEN DEEMED WORTH MENTIONING IN THIS PAPER, WHERE, FINALLY, LAW IS DESCRIBED AS A DYSTOPIA AND SOME POSSIBLE ALTERNATIVE ACTIONS ARE SUGGESTED FOR RECONSTRUCTING A CONTEMPORARY JUSPHILOSOPHIC DISCOURSE ON JUSTICE AS A MEANS TO EFFACE TODAY'S PARTICULARLY AUTHORITARIAN AND MERCILESS SOCIAL LIFE PATTERNS.
\end{abstract}

\section{KEYWORDS}

JUSPOSITIVISM; TECHNICIZATION; POST-INDUSTRIAL SOCIETIES; UTOPY AND DYSTOPIA; LAW AND LITERATURE.

Porque tudo isso sucederá num futuro ainda bastante remoto, podemos sorrir.

Porém, daqui a dez ou vinte anos parecerá, possivelmente, um pouco menos divertido. Porque o que é agora mera ficção científica, tornar-se-á um fato político de todos os dias. ${ }^{1}$ 


\section{INTRODUÇÃO}

Em sua carta XCV, o filósofo estoico Sêneca nos aconselha a termos não apenas na boca, mas também no coração o verso do comediógrafo Terêncio, ativo no século II a.C.: "Homo sum: humani nihil a me alienum puto", ou seja, "Sou homem e nada do que é humano me é alheio". ${ }^{2}$ O grande orador romano dirigiu este conselho ao seu discípulo Lucílio, aspirante a estoico com quem ele trocou cartas durante os últimos anos de sua vida. Contudo, em um exercício de imaginação histórica, poderíamos entender que essa exortação tenha sido dirigida a nós, juristas do século XXI, que lidamos em nosso cotidiano com um direito cada vez mais apartado daquilo que é humano e que parece ter se esquecido da famosa definição de Justiniano, para quem todo direito existe para servir ao homem: "Hominum causa omne jus constitutum est". 3

Este artigo pretende refletir brevemente sobre o fenômeno da desumanização das ordens jurídicas. A humanização dos ordenamentos contemporâneos - tão necessária quanto urgente - somente pode ser concretizada se conhecermos as causas que levam à desumanização, bem como as consequências que podem advir do aprofundamento desse processo. Essa constitui mais uma lição dos filósofos estoicos que, à semelhança dos médicos, afirmavam que somente podemos conceber a cura se conhecermos bem a doença.

Buscamos seguir certa ordem na exposição das ideias, ainda que, em alguns momentos, os tópicos possam parecer algo desconectados. Tal se dá em razão da simplificação de um tema naturalmente complexo, motivo pelo qual passamos a descrever o sentido básico de nossa argumentação. Em primeiro lugar, impõe-se uma análise da chamada tecnicização do direito, que constitui algo diverso do formalismo jurídico propugnado pelo juspositivismo. Dessa forma, veremos no item 1 que, ao contrário do que muitos autores sustentam, o positivismo jurídico não pode ser culpado pelo esvaziamento do direito enquanto ordem socionormativa e pela sua compreensão meramente técnica. Há várias causas para tanto. Abordaremos uma delas em profundidade no item 2, qual seja, a unidimensionalização das sociedades pós-industriais. No item seguinte descreveremos o direito enquanto distopia, não sem antes esclarecer o que se deve entender pelos termos "utopia" e "distopia”. Eis a parte mais importante deste artigo, já que aponta para as possíveis consequências nefastas da desumanização do direito, que, se não for superada, poderá nos levar a formas de convívio social particularmente autoritárias e perversas. Por enquanto, tais formas só existem em romances distópicos de ficção científica, razão pela qual nos valeremos de alguns deles para nossa projeção, lançando mão de um dos métodos da escola de pensamento jurídico que hoje é conhecida nos EUA e na França como "Direito e Literatura". 4

A literatura, mais do que as outras artes, expressa toda a grandeza e a miséria do ser humano. Nela encontramos a narração essencial do que é o homem, que, afinal, se apresenta como o destinatário de todas as normas jurídicas. E quanto maior for o 
nosso conhecimento sobre o ser humano, mais perfeito será o nosso entendimento propriamente jurídico. Assim, tudo que é literário interessa ao jurista. Conforme já afirmamos em outro contexto, ${ }^{5}$ a análise empreendida pela ciência do direito tem muito a ganhar ao buscar as matrizes do discurso jurídico em obras literárias paradigmáticas em determinados períodos históricos, pois ao mesmo tempo em que refletem a concepção de direito relativa à cultura a que pertencem auxiliam a formular outras tantas concepções que a sucederão. A literatura - que, de certo modo, desmascara as camadas ideológicas que recobrem a racionalidade jurídica, criticando-a e desmistificando-a - sempre foi pródiga, em quantidade e em qualidade, quando se trata de travar diálogos - quase nunca pacíficos - com o direito.

Ao final, ofereceremos uma conclusão que pretende unificar tudo o que foi dito anteriormente.

\section{Formalismo CIENTÍfico E TECNICIZAÇÃo DO DIREITO}

Há várias formas de se definir o direito. Interessa-nos, neste artigo, o direito enquanto conjunto de normas que regulam a vida social, em especial quando se trata de Estados. Neste sentido, entendemos que o direito se define enquanto ordem jurídica centralizada. ${ }^{6}$ Trata-se de conceituação ampla e formal, pois acreditamos que o fenômeno jurídico não é cientificamente cognoscível mediante a análise de seu conteúdo. Com efeito, o direito pode apresentar qualquer conteúdo, como asseverou Kelsen em várias oportunidades. ${ }^{7}$ Certos traços formais são necessários e suficientes para qualificar determinadas experiências sócio-organizativas como jurídicas, independentemente do conteúdo justo ou injusto das normas que as conformam. Verificar a justiça ou a injustiça de certa ordem jurídica é uma operação intelectual que envolve juízos de valor, elementos que não são levados em conta por uma teoria jurídica positivista em razão da subjetividade e da relatividade com que são formulados. Entendemos que a presença de um poder centralizado monopolizador da coerção em determinado território no qual vive certo número de indivíduos constitui-se como ordem jurídica.

Não há dúvida quanto ao formalismo desse conceito, que abstrai os ordenamentos jurídicos reais e históricos para, retendo os traços formais que os igualam, descrever o direito enquanto experiência de caráter universal. Tal procedimento analítico-abstrato não se diferencia dos métodos científicos tradicionais, que buscam conhecer as coisas enquanto espécies ou elementos subsumíveis em modelos e categorias já existentes. Trata-se do conhecido e rigoroso método positivista - tão atacado e tão incompreendido -, que prefere descrever as coisas como são e não como deveriam ser. Busca-se, assim, um conceito de direito axiologicamente neutro, o que garante um maior campo de atuação à ciência jurídica enquanto tal. Da mesma forma que um conceito de "tempo bom” seria inútil para a meteorologia, que, por razões óbvias, necessita de uma categoria operacional mais absorvente e universal tal 
como "tempo", que pode ser, em um segundo momento, bom ou mau, o juspositivista entende que não há qualquer valor científico-definitório em um conceito de “direito justo". ${ }^{8}$ Não é aqui o lugar para uma defesa do método positivista enquanto experiência epistemológica válida - talvez a única verdadeiramente válida - , dado que tal não se encaixa no objeto deste estudo. ${ }^{9}$ Apenas queremos fazer notar, a título introdutório, que só é possível fazer ciência do universal, como, aliás, já dissera Aristóteles. Fatos e situações particulares não se prestam às inevitáveis generalizações de que as ciências precisam lançar mão a fim de conhecer os seus objetos de estudo, motivo pelo qual um conceito minimamente científico de direito deve se limitar à forma.

Contudo, um conceito formal de direito como o que defendemos não se desdobra necessariamente em uma formulação de exclusiva feição técnica e, muito menos, em uma prática jurídica empobrecida. A exigência formal advém do rigor científico, sendo, portanto, claramente instrumental, já que nenhuma ciência se reduz a si mesma. A descrição científica do fenômeno jurídico como forma universal não implica a redução dos ordenamentos jurídicos descritos a conjuntos de normas que apresentam apenas significado formal. Em uma palavra: o positivismo jurídico não traz consigo, como querem os seus detratores, uma prática jurídica real forçosamente formalista e descompromissada com os valores. Descrição científica do direito não significa tecnicização do direito. Aceito este pressuposto, muitas das críticas inconsequentes dirigidas ao positivismo jurídico perdem o significado. Se o direito das sociedades pós-industriais se torna mais e mais técnico, afastando-se dos fins para os quais toda norma jurídica é criada, tal não pode ser imputado acriticamente ao positivismo jurídico, que apenas exige rigor formal e não esvaziamento axiológico do direito enquanto ordenamento social. A progressiva redução do direito a mera técnica de controle social liga-se a outras questões muito mais profundas, muitas delas anteriores ao surgimento do positivismo jurídico enquanto teoria. Obviamente, o tema apresenta grande complexidade, razão pela qual indicaremos apenas algumas das causas de tecnicização do direito, alertando para o perigo ínsito desse processo que vem ocorrendo em vários Estados tidos como "desenvolvidos".

Pois bem, o esvaziamento tecnicista do direito se entremostra principalmente nos seguintes fenômenos: a) intensa inflação legislativa acompanhada de altos índices de ineficácia normativa, ainda que seletiva; b) desconsideração das finalidades últimas das normas jurídicas por parte de seus aplicadores, em especial o Poder Judiciário, apegado a fórmulas processuais em detrimento da tutela jurisdicional efetiva; c) tendência a excessiva regulamentação infralegal de questões econômico-financeiras por parte do Poder Executivo, o que, na prática, equivale à inutilização do Poder Legislativo, muitas vezes tramada por este último em conluio com o primeiro; d) baixo grau de interesse da população em geral pela discussão de temas político-jurídicos; e) paulatina indiferenciação entre o espaço público e o privado, com a consequente invasão da 
esfera individual por entidades governamentais ou não; f) impossibilidade real de o Estado fazer valer normas jurídicas contrárias a interesses de grupos sociais poderosos, sejam eles legais ou não; g) relativização de direitos fundamentais em nome de necessidades técnicas, especialmente quando apresentam natureza fiscal, contábil ou econômico-administrativa.

\section{O DIREITO UNIDIMENSIONAL}

Nas sociedades pós-industriais há uma sensação crescente de alienação jurídico-normativa. Já não sabemos por que o direito existe, a quem devemos efetivamente a sua criação e, ainda mais importante, por que razão somos obrigados a cumprir os seus mandamentos. Os cenários da tecnicização do direito apontados no final do item 2 não são os únicos, mas certamente nos auxiliam a compreender esse fenômeno mediante o qual o direito se põe como corpo estranho nas relações sociais, representando de maneira muito frequente papéis hostis, particularistas e desestabilizadores. Como parece claro a qualquer um que lide com o direito diuturnamente, a racionalidade há muito abandonou a seara do fazer jurídico prático, entregue a fórmulas envelhecidas e ineficazes, dominado por imposições alheias à tessitura jurídico-científica e ancorado a interesses de ordem econométrica. O direito contemporâneo se desumaniza a passos largos e, com isso, perde a base de legitimidade que deveria fundá-lo e mantê-lo enquanto ordem normativa vinculada à convivência social. Tal pode ser percebido em várias situações e os exemplos são muitos. No cenário internacional, basta citar as violentas repressões estatais - sempre calcadas em argumentos jurídico-formais - às manifestações pacíficas recentemente ocorridas em Portugal, na Espanha e na Grécia por parte daqueles que, não desejando assumir o prejuízo derivado da crise econômico-bancária mundial, exigiam de seus governos uma nova ordenação dos pactos sociais. Em Madrid, no dia 26 de setembro 2012, os 6.000 manifestantes que clamavam por uma nova Constituição diante do parlamento espanhol foram brutalmente espancados pela polícia na frente das câmeras de televisão, em pleno centro político, comercial e turístico da cidade. No que diz respeito ao Brasil, três rápidos exemplos demonstram como o direito cada vez mais se descompromete com suas finalidades sociais, justificando sua postura de maneira "técnica". Referimo-nos à violenta desocupação de Pinheirinhos em São Paulo; à proibição, em várias cidades do país, da marcha da maconha; e, finalmente, à famigerada Lei Geral da Copa, que suspende diversas normas jurídicas brasileiras (Lei de Licitações, Código de Defesa do Consumidor etc.) para possibilitar a realização de evento futebolístico conforme a vontade "soberana" da FIFA. Nessas três situações, percebemos que aos cidadãos brasileiros são negados direitos básicos, tais como moradia, devido processo legal e liberdade de expressão. Todavia, tais atos denegatórios de direitos não seriam - pelo menos conforme seus idealizadores - "ilegais", mas plenamente "legítimos", eis que 
seguiram certos procedimentos e regras formais do ordenamento jurídico nacional. Ao que nos parece, isso só pode significar que um sistema jurídico democrático pode ser facilmente utilizado para a realização de propósitos autoritários.

Marcuse nota que nas sociedades pós-industriais em que vivemos há uma espécie de substituição e sublimação das formas de dependência. Se antes a dominação se dava por meio da dependência pessoal - do escravo em relação ao senhor, por exemplo -, nos dias de hoje ela se vincula ao que o autor chama de "ordem objetiva das coisas", não identificável como antes o eram o patrão ou a classe burguesa. Os novos senhores do mundo são as evanescentes leis do mercado, os princípios econômicos, as necessidades nacionais, o interesse público etc. Essa “ordem objetiva das coisas” é certamente o resultado de processos sociais de dominação, mas ela própria impõe novas formas de servidão, fundadas em uma racionalidade unidimensional que se corporifica no aparato técnico prevalecente que a reproduz. ${ }^{10}$ Ora, o direito contemporâneo nada mais é do que uma parte desse aparato, que "[...] derrota o seu próprio objetivo se este é criar uma existência humana com base numa natureza humana”. ${ }^{1}$

Todas as formas de organização político-jurídicas conhecidas se baseiam na imposição de certos padrões de conduta ao indivíduo e na proteção a um número limitado de valores que constituem o que costumamos chamar de cultura. Isso quer dizer que a sociedade se fundamenta em mitologemas que, na maior parte das situações, são aceitos de bom grado pelas pessoas. Significa dizer que o indivíduo, considerado enquanto tal e não como um número a ser contado de tempos em tempos - nas eleições, por exemplo - tem participação escassa ou nula na condução do seu próprio destino social. Vale frisar uma vez mais: todas as formas de organização político-jurídicas - da tribo indígena ao Estado, da Comuna de Paris à Alemanha de Hitler precisam necessariamente da obediência do indivíduo para se manter efetivas. Assim, as pessoas abrem mão de suas consciências em favor de certas abstrações (v.g., interesse público) e ideias mal compreendidas (v.g., democracia, essa espécie de "[...] ratificação pública das decisões governamentais”), ${ }^{12}$ crendo que tal corresponde à única forma de convivência humana em contextos sociais complexos. A obediência, portanto, constitui o cerne mesmo de qualquer sistema social. Sem ela, torna-se impossível garantir uma convivência mais ou menos aceitável e segura, conforme sustenta insistentemente o poder constituído.

Contudo, há momentos de grave crise na tessitura social que levam as pessoas a repensarem papéis há muito estabelecidos. Em tais situações, que são de variadas ordens, abarcando desde as revoluções até os movimentos terroristas, ${ }^{13}$ o indivíduo pode ser levado a se questionar acerca da legitimidade do poder social que o oprime. Aflora então a ideia de desobediência, entendida como uma negativa peremptória ao governo e a qualquer forma de normatização heterônoma, ou seja, qualquer ordem que não encontre nascedouro na consciência individual. Pode-se objetar que hipóteses assim somente se verificam em condições muito específicas, e que o normal, caso 
se queira manter a convivência humana em padrões razoáveis de previsibilidade e de segurança, é a obediência. Todavia, tal argumento se funda em uma postura epistemologicamente discutível que identifica o normal, o usual ou o costumeiro com o melhor ou de qualquer forma com o mais valioso. Na verdade, a questão que se coloca não é "quando desobedecer?" ou “a quem desobedecer?", mas sim "por que obedecer?”. A resposta pode parecer óbvia para quem se beneficia com a atual configuração das sociedades humanas por assim dizer obedientes, mas se torna bem mais interessante se tiver de ser respondida pela enorme massa que, na verdade, não encontra vantagens substanciais na submissão diuturna, e que, de resto, não tem condições de realmente responder à questão, posta de maneira exclusivamente emocional e em contextos especiais.

A possibilidade de resistência e de desalienação em sociedades como as nossas é ínfima, uma vez que decresce diante do aumento da pretensa racionalidade técnica que a fundamenta. Essa razão unidimensional que desumaniza não apenas o direito do mundo contemporâneo, mas a sociedade como um todo, impede que o indivíduo tome consciência do processo de sujeição desumanizante ao qual é continuamente submetido pela "ordem objetiva das coisas". ${ }^{14}$ John Dolan é incisivo: "Não é que às pessoas faltará coragem para exprimir seus pensamentos fora dos limites permitidos: é que elas se tornam incapazes de pensar assim”. ${ }^{15} \mathrm{O}$ nível de crítica interna ao sistema se aproxima do zero absoluto ${ }^{16}$ quando os indivíduos não conseguem se desvencilhar das necessidades impostas artificialmente ${ }^{17}$ e as verdadeiras carências vitais e espirituais são sufocadas de modo sistemático. Isso gera uma espécie de neurótica bestialização social, situação na qual o protesto individual passa a ser visto como algo impotente e mesmo ridículo. ${ }^{18}$

No que se relaciona ao direito, Marcuse entende que as garantias e liberdades que foram vitais nas fases iniciais da sociedade industrial se renderam à etapa mais avançada que vivenciamos, já que perderam seu sentido lógico e seu conteúdo tradicionais. Conforme a lúcida previsão de Huxley em 1958, os Códigos e as Constituições não desapareceram no século XXI, mas passaram a ser formas liberais que servem apenas para dissimular uma substância sociopolítica profundamente não liberal. ${ }^{19} \mathrm{Os}$ chamados direitos fundamentais foram ideias críticas que prepararam a transição de uma forma de sociedade semimoderna para a verdadeira modernidade. ${ }^{20}$ Hoje, tais direitos estão deslocados no contexto de ordenamentos jurídicos essencialmente técnicos, em que são vistos como entraves ao nível ótimo de produção e circulação de bens materiais. Direito de oposição política, crítica às formas estabelecidas e afirmação da consciência individual são apenas palavras vazias se contrapostas à satisfação das necessidades artificiais que a sociedade unidimensional impõe. Se conseguirmos comprar o carro do ano, tanto faz que tal se dê em um Estado totalitário ou não. Conforme adverte Marcuse: "Nas condições de um padrão de vida crescente, o não conformismo com o próprio sistema parece socialmente inútil, 
principalmente quando acarreta desvantagens econômicas e políticas tangíveis e ameaça o funcionamento suave do todo", ${ }^{21}$ já que "[...] uma falta de liberdade confortável, suave, razoável e democrática prevalece na civilização industrial desenvolvida”. ${ }^{22}$ É nesse contexto acrítico, alienante e unidimensionalizado que o direito passa a representar um papel distópico que, como veremos, tende a agravar-se com a sua crescente tecnicização.

\section{Utopia E Distopia}

"Utopia" é um termo corrente na filosofia política, que pretende evocar uma espécie de sociedade ideal. Formada por dois termos gregos, ou (oú, prefixo grego de negação) е tópos (то́тоऽ, literalmente: lugar), designa, portanto, o não lugar, quer dizer, a sociedade excelente que, em razão dessa mesma excelência, não existe no mundo real. ${ }^{23}$ Segundo Antônio Houaiss, o termo foi utilizado pela primeira vez na língua portuguesa em uma obra publicada no ano de 1671 na cidade de Lisboa e que levava o curioso título de Escola das verdades aberta aos Princepes na lingua italiana, por o Pe. Luiz Juglares da Companhia de Jesus, e patente a todos na Portugueza por D. Antonio Alvares da Cunha. ${ }^{24}$ No Dictionnaire de l'Académie (1798), o termo assume nítido conteúdo político-jurídico, pois define um "plan de gouvernement imaginaire”. Mas bem antes desta definição a palavra "utopia” havia se tornado justamente célebre graças a seu inventor, Thomas More, humanista inglês do final do século XV e início do XVI, que em sua obra homônima apresentou o projeto político da ilha de Utopia, em que os seus habitantes gozavam de um sistema jurídico igualitário, liberal e justo. ${ }^{25}$ Além de More, foram também famosos utopistas da modernidade o filósofo italiano Tommaso Campanella, autor de $A$ cidade do Sol, de 1623, e o filósofo inglês Francis Bacon, autor da utopia tecnocientífica $A$ nova Atlântida, publicada postumamente em 1627. Na contemporaneidade, destaca-se a posição dos marxistas, para quem as utopias são irrealizáveis por não se vincularem às condições estruturais concretas da sociedade, razão pela qual não devem ser nem sequer consideradas. Diferentemente, Karl Mannheim e Ernst Bloch acreditam no potencial transformador das utopias, capazes de alimentar o desejo de mudanças sociais e assim oferecer vias alternativas para a organização político-jurídica real. Para Mannheim, a utopia somente é vista como inalcançável por determinada estrutura social. Na realidade, trata-se de uma ideologia revolucionária que objetiva transcender a situação histórica e, por meio da ação efetiva de grupos sociais, atingir um patamar de organização social que as instituições político-jurídicas existentes não contemplam. ${ }^{26}$ Aldo Maffey entende que as utopias são projeções de desejos não totalmente satisfeitos em determinadas situações históricas, como os jardins e os oásis que povoam as mil e uma noites dos árabes exilados no deserto. Contudo, tais projeções apenas assumirão o status de utopias políticas se apresentarem um ideal a ser realizado por uma organização comunitária 
que ofereça soluções definitivas para os problemas socioeconômicos, dado que o utopista político sempre se refere ao melhor mundo realizável, e não ao melhor mundo fantasiosamente pensável, como os literatos. ${ }^{27} \mathrm{Na}$ realidade, as várias utopias políticas constituem uma aposta irrestrita no poder da razão humana, que aliada à ideia de progresso, típica do iluminismo, seria capaz de garantir às sociedades humanas formas mais justas de organização social.

Todavia, existem também as distopias político-jurídicas. O prefixo grego dys

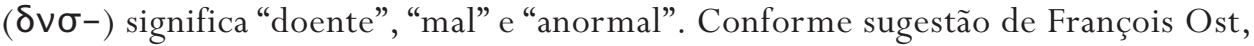
evidenciada em sua análise das fontes do imaginário jurídico contidas nas obras de Franz Kafka, ${ }^{2}$ as distopias seriam utopias às avessas, ou seja, más utopias, sociedades imaginárias nas quais as condições de existência são muito piores do que aquelas das sociedades reais. Parece que o termo "distopia" foi utilizado pela primeira vez em 1868 por Greg Webber e John Stuart Mill em um discurso no Parlamento Britânico. 29

O papel do direito nas distopias é sempre marcante, apresentando-se como ordenamento eminentemente técnico cuja única função consiste em garantir a perpetuação da dominação social. Ocioso acrescentar que as sociedades distópicas se caracterizam pela inexistência de direitos e garantias fundamentais, sendo altamente autoritárias, quando não totalitárias. A principal vítima sacrificada no altar dos ainda fictícios Estados distópicos é, sem dúvida alguma, a liberdade. Para compreendermos melhor o que vem a ser uma distopia, tomemos as palavras de O’Brien, membro do IngSoc (Socialismo Inglês, em novilíngua), partido único que governa a Oceania, Estado imaginado por George Orwell em seu romance 1984:

Começas a distinguir que tipo de mundo estamos criando? É exatamente o contrário das estúpidas utopias hedonísticas que os antigos reformadores imaginavam. Um mundo de medo, traição e tormentos, um mundo de pisar ou ser pisado, um mundo que se tornará cada vez mais impiedoso, à medida que se refina. O progresso em nosso mundo será o progresso no sentido de maior dor. As velhas civilizações proclamavam-se fundadas no amor ou na justiça. A nossa funda-se no ódio. Em nosso mundo não haverá outras emoções além de medo, fúria, triunfo e autodegradação.

Destruiremos tudo mais, tudo. Já estamos liquidando os hábitos de pensamento que sobreviveram de antes da Revolução. Cortamos os laços entre filho e pai, entre homem e homem, mulher e homem. Ninguém mais ousa confiar na esposa nem nos amigos. As crianças serão tomadas das mães ao nascer, como se tiram os ovos da galinha. O instinto sexual será extirpado. A procriação será uma formalidade anual como a renovação de um talão de racionamento. Aboliremos o orgasmo. Nossos neurologistas estão trabalhando nisso. Não haverá lealdade, exceto lealdade ao Partido. 
Não haverá amor, exceto amor ao Grande Irmão. Não haverá riso, exceto o riso de vitória sobre o inimigo derrotado. Não haverá nem arte, nem literatura, nem ciência. Quando formos onipotentes, não teremos mais necessidade de ciência. Não haverá mais distinção entre a beleza e a feiura. Não haverá curiosidade, nem fruição do processo da vida. Todos os prazeres concorrentes serão destruídos. Mas sempre... não te esqueças, Winston... sempre haverá a embriaguez do poder, constantemente crescendo e constantemente se tornando mais sutil. Sempre, a todo momento, haverá o gozo da vitória, a sensação de pisar um inimigo inerme. Se queres uma imagem do futuro, pensa numa bota pisando um rosto humano, para sempre. ${ }^{30}$

A distância entre a utopia e a distopia é pequena e pode ser apenas uma questão de opinião e de juízos de valor. G. Kaleb acentua que "o utopista inicia no amor e termina no terror”. ${ }^{31}$ Uma vez postas em ação, as utopias não podem ser controladas, e muitas vezes pretendem libertar ou tornar felizes os homens independentemente de suas próprias vontades. A missão de toda utopia é regenerar as pessoas, ainda que precise enfrentá-las e impor-lhes este alto destino. ${ }^{32}$ Eis o caminho que imperceptivelmente nos leva da utopia ao seu gêmeo fantasmático, ao seu doppelgänger: a distopia. Assim, na tão louvada República ${ }^{33}$ de Platão, por exemplo, não há lugar para a liberdade individual. Recordemo-nos que Platão entende ser a democracia uma forma corrompida de governo, motivo bastante para reservar a direção da sua cidade ideal unicamente aos sábios, que exerceriam o poder de forma autoritária. Ademais, o Estado platônico se assemelha a um esboço do Estado totalitário que a contemporaneidade conheceu, pois controla todos os aspectos da vida social, desde a educação das crianças - que seriam separadas dos pais na mais tenra infância - até a alocação dos indivíduos nos seus respectivos ofícios e profissões, o que se daria por meio de critérios objetivos estabelecidos pela pólis e não em razão da decisão pessoal dos próprios interessados. Eis um detalhe interessante que retrata bem a república "ideal" de Platão: apesar de reconhecer o encantamento que a poesia exerce sobre os cidadãos, os poetas deveriam ser expulsos da pólis. É que, de acordo com Platão, a condenação da poesia se impõe racionalmente pelo fato de não ser útil ao Estado nem à vida humana. ${ }^{34}$ Para um poeta, certamente a cidade platônica seria antes uma distopia do que uma utopia.

Mais escandalosa ainda que a república platônica seria a cidade ideal de Zenão de Cício, o fundador da austera escola estoica grega. ${ }^{35}$ Para ele, somente os sábios ostentariam o status de cidadãos; os demais deveriam ser reduzidos à condição de escravos e tratados como inimigos. Informado pelas concepções éticas do cinismo corrente filosófica helenística que criticava acidamente os padrões comumente aceitos de sociabilidade e de moralidade -, Zenão proíbe a construção de templos, de 
ginásios e de estádios. Na cidade zenoniana não existiria comércio ou propriedade privada, sendo que homens e mulheres deveriam se vestir da mesma maneira, deixando o corpo à mostra sempre que possível. Aliás, as mulheres seriam compartilhadas por todos. Ao sábio tudo estaria permitido, até mesmo a prostituição, o estupro, o incesto e o canibalismo. Por mais escabrosas que possam parecer estas ideias, Zenão e seu segundo sucessor à testa da Stoá, Crisipo, as justificavam racionalmente. Contudo, mais do que um projeto político-jurídico realista, a república zenoniana era uma provocação à decadente pólis grega, que se pavoneava de maneira vaidosa e falsa de uma glória que já não mais possuía desde a submissão a Alexandre e, posteriormente, a Roma.

Todavia, as distopias não foram um gênero literário comum na Antiguidade e, obviamente, nem Platão e nem Zenão apresentaram os seus sistemas de governo como realidades negativas. Ao contrário: tanto no mundo antigo quanto no medieval ou moderno multiplicaram-se as utopias sociais, algumas descambando para os sonhos mais fantasiosos e ousados. Um prenúncio do que seriam as distopias pósmodernas pode ser encontrado na obra de Donatien-Alphonse-François, o Marquês de Sade, que no curioso panfleto político Franceses, mais um esforço se quereis ser republicanos, ${ }^{36}$ propõe um Estado erotizado onde todos deveriam se submeter aos caprichos sexuais de todos, inaugurando uma verdadeira era de liberdade na qual não existiria limite para a satisfação sensual do cidadão, ainda que o prazer de alguns pudesse custar a vida de outros. Sade entende que o Estado deve criar e manter instituições apropriadas para a satisfação de todos os tipos de luxúria, inclusive o incesto que, segundo o escritor francês, tornam mais apertados os laços de família e mais ativo o amor dos cidadãos pela pátria. Estariam ausentes da república de Sade todas e quaisquer formas de religião e teísmo. Não obstante o seu caráter polêmico, o projeto político de Sade se mostra ingênuo diante dos pesadelos totalitários engendrados no século XX, especialmente rico em distopias. ${ }^{37}$ Ainda que delirante, a república de Sade objetivava proteger o indivíduo diante da ação despótica do poder estatal. Apesar da pecha de depravado e de louco, o genial marquês era um filho legítimo do século XVIII, e mais ainda da Revolução Francesa, que objetivou extinguir o absolutismo monárquico em nome das liberdades públicas do cidadão. Se seguirmos o fio da argumentação de Sade, veremos que a revolução nos costumes por ele proposta tem um sentido bastante claro: impedir que as pulsões sexuais não satisfeitas do homem sejam sublimadas em formas autoritárias de exercício do poder político. Para Sade, o libertino insatisfeito de hoje é o déspota de amanhã, que desconta na sociedade a sua frustração sexual sob a forma de um governo tirânico. Assim, há que se evitar que todos nós nos tornemos pequenos ditadores. O único caminho para tanto seria a institucionalização dos prazeres e de todos os vícios que os acompanham. Nem é preciso dizer como esse texto de Sade agradou aos psicanalistas, de Freud a Lacan. 
Importa notar, contudo, que a distopia de Sade ainda se relaciona a uma longa tradição libertária europeia na qual o poder do Estado sobre os cidadãos é constantemente questionado. Essa foi a tônica do século XVIII. No entanto, o século XX celebrizou-se por produzir distopias em que o indivíduo se encontra submetido de modo total à autoridade do Leviatã. E o mais assustador: a história recente do Ocidente está a demonstrar e a comprovar a possibilidade técnica de realização dessas distopias político-jurídicas autoritárias, cada vez menos fictícias. Não poderia ser diferente: os enormes avanços tecnológicos somados à desagregação ética que assola o nosso tempo produziram visões de futuro em que o direito passou a ser mero instrumento de dominação e de desumanização. Impossível pensar em uma sociedade universal justa e livre após os horrores dos totalitarismos, testemunhas da capacidade de infinita crueldade, em escala global, de que os homens são capazes.

Bertrand Russell ${ }^{38}$ entende que a mentalidade contemporânea já não consegue conceber como factíveis as sociedades sonhadas por um More, por um Campanella ou até mesmo por um Marx; falta-nos imaginação - e talvez inocência - para tanto. Prova disso é que o produto típico dos delírios político-jurídicos pós-modernos - as distopias - nada mais é do que exacerbações dos traços negativos efetivamente existentes nas sociedades concretas e atuais. Talvez mais grave do que perdermos a capacidade de sonhar é perdermos também toda a capacidade criativa mesmo nos pesadelos. Somos obrigados a encarar as nossas próprias sociedades corruptas e desumanizadas em um espelho - deformador, é verdade - que, ao fim e ao cabo, apenas nos mostra a que ponto chegaremos. A diferença entre o mundo em que vivemos e os pesadelos tecnototalitários dos romances de George Orwell (1984), ${ }^{39}$ Aldous Huxley (Admirável mundo novo) ${ }^{40}$ e Anthony Burgess (Laranja mecânica) ${ }^{41}$ é apenas de grau, não de natureza. Já temos entre nós um Grande Irmão - conforme descrito por Orwell - que nos vigia, que vela por nós. Dia a dia, ao ligarmos a televisão (precursora das onipresentes teletelas?), ao lermos os jornais, ao nos conectarmos à internet, percebemos a ação de um invisível Ministério da Verdade que acaba por nos convencer de que Guerra é Paz, Liberdade é Escravidão e Ignorância é Força. Da mesma forma que os personagens imbecilizados do célebre romance de Huxley, já consumimos diariamente a nossa ração de soma, droga que teria por função proporcionar aos habitantes do admirável mundo novo doses diárias de alegria barata, entorpecendo-as e submergindo-as em uma colorida realidade de desejos fúteis e sensações gratuitas de prazer, tornando-as, assim, dóceis e submissas ao domínio governamental. E falando em drogas, a política patética, mentirosa e ineficiente dos governos mundiais que, para deleite da tacanha opinião pública, afetam uma rígida, santa e inquestionável cruzada contra as drogas, lembra a realidade apocalíptica de $O$ homem duplo, ${ }^{42}$ de Philip K. Dick, novela de ficção(?)-científica em que o governo ao mesmo tempo em que combate o tráfico e o uso de drogas as produz e distribui por meio de uma empresa, efetiva dona do Estado. Este, por seu turno, vicia inclusive os 
seus próprios agentes de segurança pública em um sistema perverso no qual prevalece um clima de denuncismo, desconfiança e medo. Os métodos de reeducação social concebidos por Burgess em seu romance e levados ao cinema com grande êxito por Stanley Kubrick transformaram o delinquente Alex, antes interessado apenas em estupro, ultraviolência e Beethoven, em um pacato e responsável cidadão incapaz de qualquer ato de violência, tanto que sente náuseas e desmaia ao tentar se defender da ação de alguns marginais, antigos conhecidos seus dos tempos de débauche. Ora, não é essa a tônica dos mais avançados sistemas penais do planeta, que pretendem forçar o homem a ser "bom" - ressocializá-lo, dizem os penalistas - para logo depois despejá-lo em um mundo que continua a ser "mau”?

Orwell anteviu a lógica da submissão e do controle na novilíngua, uma espécie de idioma universal gestado em laboratório e que deveria, pouco a pouco, substituir a anticlíngua (o inglês) no imaginário Estado da Oceania, onde é ambientada a sua distopia. A novilíngua seria de uma pobreza e de uma simplicidade extremas, mostrando-se inapta para a expressão de qualquer pensamento mais profundo. Com a progressiva imposição desse novo idioma, as pessoas perderiam a capacidade de pensar e de se revoltar contra o sistema porque já não teriam um veículo linguístico capaz de expressar pensamentos complexos; a comunicação reduzir-se-ia ao mínimo necessário para a sobrevivência. O ideal da novilíngua seria oferecer ao indivíduo um número cada vez menor de palavras com significados cada vez mais restritos, de modo que seria impossível expressar significados divergentes da vontade do partido governante. Por exemplo: as palavras "livre" e "igual" poderiam inclusive existir, mas jamais evocariam a liberdade de pensamento ou a igualdade de direitos, já que tais situações subjetivas deixaram de existir há muitas gerações na Oceania. Orwell assevera que seria impossível traduzir para a novilíngua o trecho inicial da Declaração de Independência dos Estados Unidos da América, na qual se afirma que existem alguns direitos inalienáveis tais como a vida, a liberdade e a busca da felicidade, e que a função do governo é garanti-los, sob pena de ser derrubado e substituído por outro pelo povo, único detentor do poder político. A tradução mais aproximada seria a substituição de todo o trecho por uma única palavra da novilíngua: "crimepensar". 43 Ora, a novilíngua já não está parcialmente presente nos nossos noticiários sempre comprometidos com o poder, nos discursos vazios de nossos representantes políticos e nos pronunciamentos infantis e superficiais de figuras como George Bush, que querem nos fazer acreditar que os EUA têm a missão sagrada de combater o mal onde quer que ele esteja, em uma espécie de faroeste planetário em que eles são os xerifes?

Quanto à cultura, já sobrepujamos os sonhos negros de Huxley e de Bradbury (Fahrenheit 451), ${ }^{44}$ romancistas que imaginaram um futuro em que os livros seriam proibidos e impiedosamente destruídos pelo Estado, por conterem ideias subversivas que ameaçam a estabilidade e a paz social. Hoje não precisamos dos bombeiros de Bradbury, cuja missão irônica e paradoxal não era apagar incêndios, mas sim queimar 
livros. Não há necessidade de temermos um Selvagem como o de Huxley, cujo grande crime era ler Shakespeare em uma sociedade que já tinha se esquecido das dores e das alegrias humanas concentradas nos versos do bardo inglês. A forma de dominação a que nos submetemos é muito mais sutil e eficiente, pois somos levados a acreditar que a cultura, em termos amplos, não nos trará quaisquer vantagens: ter é muito mais importante do que ser e saber. Ter é poder, e as ambições econômicas sobrepujam quaisquer considerações éticas ou estéticas. Não é preciso queimar livros em uma sociedade que os despreza.

É especialmente notável que nas maiores distopias do século XX o gosto pela cultura, pela arte e pela ciência venha associado a personalidades tidas como degeneradas, sempre prontas para contestar a ordem social vigente, vistas, portanto, como indivíduos a serem reeducados, o que inclui primordialmente a extinção dos seus pendores culturais. Alex, o anti-herói de Burgess, é um sociopata extremamente violento que respeita uma única coisa na vida: a música de Beethoven, o "divino Ludwig”. O personagem principal de 1984, Winston Smith, sente-se deslocado diante das situações culturalmente pobres e homogeneizantes a que é obrigado a se submeter, e somente se descobre enquanto homem livre - e por isso mesmo rebelde em relação à autoridade do Grande Irmão - ao tomar contato com um livro proibido que avidamente buscava: “Teoria e prática do coletivismo oligárquico”, uma espécie de ensaio político-sociológico da autoria de Emmanuel Goldstein, o pretenso líder da resistência. Já o Selvagem de Admirável mundo novo espanta e aterroriza as pessoas com demonstrações de alegria, afeto, raiva e tristeza, emoções que aprendeu com a leitura das obras de Shakespeare e eram então desconhecidas e temíveis na asséptica realidade de Huxley. Um estuprador que idolatra Beethoven? Um rebelde cujo grande crime é ler e escrever? Um selvagem que cita Shakespeare? A mensagem contida nestes arquétipos parece muito clara: a cultura e o saber são perigosos; afaste-se deles o mais rápido possível. Se você quer ser aceito pelos outros, imbecilize-se. Se você não quer ser um peixe fora d'água, renda-se aos (des)gostos da maioria. Ela dita o que é belo, bom, correto e seguro. O resto - Beethovens, ensaios político-sociológicos, Shakespeares etc. - é inutilidade perigosa que só interessa a loucos problemáticos que, mais cedo ou mais tarde, se renderão aos padrões morais e sociais das pessoas de bem. Eis o destino que a desumanização extrema dos ordenamentos jurídicos tecnicizados reserva à alta inteligência. Nada que nos surpreenda: a cultura de verdade, contestatória por natureza, sempre gerou medo, desconforto e repulsa nas massas ignorantes e inebriadas pelas pequenas vantagens do sistema, sejam elas esmolas estatais - bolsa-isto ou bolsa-aquilo - para os miseráveis e descamisados, sejam bens de consumo artificialmente impostos às classes medianas ou superiores como necessários a uma vida "decente": o celular da moda, a roupa de grife da estação, o iPod mais potente, a boate mais cool, o restaurante mais chic, dependendo do gosto ou da idade. Aliás, não precisamos ir até às distopias. Basta 
lembrar o Ministro da Propaganda de Hitler, que dizia sacar o revólver todas as vezes que ouvia a palavra "cultura”. E o que dizer do desesperançado Ulrich, personagem do polifônico $O$ homem sem qualidades, romance de Robert Musil? No capítulo 13 da primeira parte dessa enorme enciclopédia, Ulrich, típico acadêmico austríaco do início do século passado, meio niilista, meio epicurista, meio a mistura dessas duas coisas com nada, espanta-se ao ler um jornal e nele notar que certo cavalo de corrida havia sido classificado como genial. Ele vira lutadores de boxe e jogadores de futebol serem agraciados com esse adjetivo antes reservado aos da Vincis, Mozarts e Dostoievskis, mas o fato de agora poder definir também um cavalo de corrida - companhia mais do que adequada aos jogadores de futebol - lhe parece um sinal dos tempos. ${ }^{45}$ Este capítulo do livro de Musil foi ambientado em 1913, escrito na década de 1920 e publicado em 1930, na Áustria. O que diria ele hoje, no Brasil, ao comparar os parcos e insossos suplementos culturais dos nossos mais importantes jornais com os portentosos, volumosos e avidamente lidos cadernos de esportes? É realmente um sinal dos tempos. Dos tempos das distopias.

\section{CONCLUSÃo}

A capacidade do homem de fazer o mal aos seus semelhantes é imensa. Este constitui um dos nossos traços básicos que costumamos qualificar a contragosto como "humano". Todavia, gostemos ou não do lado negro que possuímos, devemos aprender a conviver uns com os outros em um ambiente que potencialize o que há de melhor nas pessoas. Nesse contexto, o direito representa um importante papel, já que pode ser utilizado como catalisador tanto de utopias quanto de distopias. O fato de que atualmente ele venha servindo mais e mais a propósitos nitidamente distópicos, visto que autoritários, demonstra o quanto o pervertemos. Pela sua própria substância histórica, a experiência jurídica ocidental se liga à realização da liberdade enquanto valor supremo. Da Lei das XII Tábuas de 451/450 a.C., que consolidou a república romana, à Magna Charta, que os barões feudais impuseram ao Rei João sem Terra em 1215, do Édito do Imperador Caracala de 212, que estendeu a cidadania romana a todos os habitantes do Império, à Declaração de Independência das colônias britânicas em 1776, o movimento do direito ocidental tem se orientado rumo à concretização da liberdade, processo que encontra, do ponto de vista formal e material, o seu nec plus ultra na Declaração dos Direitos do Homem e do Cidadão da Revolução de 1789. Conforme ensina Salgado, nesse documento desponta a noção de sujeito universal de direitos fundamentais, entendidos estes como valores de cumeada que guiarão todo o percurso posterior da evolução jurídica ocidental, ${ }^{46}$ razão pela qual Bobbio assevera que o problema dos nossos dias não é a justificação dos direitos fundamentais - tarefa que coube basicamente ao iluminismo - mas antes a sua efetivação. ${ }^{47}$ Tendo em vista tal situação, mais urgente se põe a retomada do 
que há de humano no direito, o que não significa que ele deva se descomprometer com as exigências técnico-formais que o informam enquanto ordem centralizada de coerção. Exige-se, antes, que o direito contemporâneo se liberte das correntes subterrâneas que o envolvem e o degradam, reduzindo-o a coadjuvante de práticas políticas irresponsáveis, quando não a mero convalidador dos ditames pretensamente necessários da economia global. Com fincas em Sêneca, podemos afirmar que nada do que é humano pode ser desconsiderado pelo direito, pois ele é um instrumento humano para a solução de conflitos igualmente humanos, e não um fim em si mesmo, que se perde na autorreprodução técnica de procedimentos vazios e alienantes. Do contrário, "liberdade”, “cidadão" e mesmo "direito” serão palavras ilegais, intraduzíveis para a novilíngua de um mundo novo nem um pouco admirável. Estará aberta a via para o Grande Irmão, caminho sem volta para a servidão.

: ARTIGO APROVADO (15/05/2013) : RECEBIDO EM 05/07/2012

\section{NOTAS}

1 HUXLEY, Aldous. Regresso ao admirável mundo novo. Tradução Eduardo Nunes Fonseca. Belo Horizonte/Rio de Janeiro: Itatiaia, 2000, p. 141.

2 SÉNECA, Lucio Anneo. Cartas a Lucilio. Tradução, prólogo e notas Vicente López Soto. 3. ed. Barcelona: Juventud, 2006, XCV, 53, p. 346.

3 Corpus Juris Civilis, Digesto, I, S., 2.

4 Muito embora nos valhamos de algumas intuições de François Ost neste artigo, nosso objetivo não é discutir o estatuto teórico da corrente "Direito e Literatura", tema extremamente complexo que exigiria por si só um trabalho autônomo para debater questões tais como seus métodos e teorias - se é que existem -, suas semelhanças e diferenças em relação a correntes e posturas próximas, a exemplo dos critical legal studies e do "Direito enquanto Literatura" etc. Para uma discussão inicial desses problemas, com um bom mapeamento das posições, cf. o trabalho de GODOY, Arnaldo Sampaio de Moraes. Direito e literatura. Os pais fundadores: John Henry Wigmore, Benjamin Nathan Cardozo e Lon Fuller. In: BuscaLegis.ccj.ufsc.br. Acesso em: 9 nov. 2012. Para uma discussão mais completa, cf. BINDER, Guyora; WEISBERG, Robert. Literary criticisms of law. New Jersey: Princeton University, 2000; GODOY, Arnaldo Sampaio de Moraes. Direito \&literatura: anatomia de um desencanto. Curitiba: Juruá, 2002; e MORAWETZ, Thomas. Law and literature. In: PATTERSON, Dennis (Org.). A companion to philosophy of legal and legal theory. Malden: Blackwell, 1996.

5 MATOS, Andityas Soares de Moura Costa. Direito: perguntas e respostas. Questões teóricas, acadêmicas e ético-profissionais. Belo Horizonte: Del Rey, 2007, p. 76-79.

6 KELSEN, Hans. Teoria geral do direito e do estado. Tradução Luís Carlos Borges. 3. ed. São Paulo: Martins Fontes, 2000, p. 263. 
7 KELSEN, Hans. Théorie pure du droit. Adaptée de l'allemand par Henri Thévenaz. 2. ed. Neuchâtel: Éditions de la Baconnière, 1988, p. 122; KELSEN, Hans. Teoria geral das normas. Tradução e estudo introdutório José Florentino Duarte. Porto Alegre: Sergio Antonio Fabris, 1986, p. 70; e KELSEN, Hans. Das Problem der Souveränität und die Theorie desVölkerrechts. Tubingen: Mohr, 1920, p. III et seq.

8 HOERSTER, Norbert. En defensa del positivismo jurídico. Tradução Ernesto Garzón Valdés. Barcelona: Gedisa, 2000 , p. 21.

9 Uma defesa clássica do juspositivismo pode ser lida com grande proveito em BOBBIO, Norberto. O positivismo jurídico: lições de filosofia do direito. Tradução Márcio Pugliesi, Edson Bini e Carlos E. Rodrigues. São Paulo: Ícone, 1999. Para uma formulação mais contemporânea e igualmente incisiva, cf. DIMOULIS, Dimitri. Positivismo jurídico: introdução a uma teoria do direito e defesa do pragmatismo jurídico-político. São Paulo: Método, 2006.

10 MARCUSE, Herbert. A ideologia da sociedade industrial: o homem unidimensional. Tradução Giasone Rebuá. 6. ed. Rio de Janeiro: Zahar, 1982, p. 142-143.

11 MARCUSE, Herbert. Op. cit., p. 143.

12 CHOMSKY, Noam. Piratas \& imperadores, antigos \& modernos: o terrorismo internacional no mundo real. Tradução Milton Chaves de Almeida. Rio de Janeiro: Bertrand Brasil, 2006, p. 16.

13 “A sugestão de que haja certa analogia no exercício de direitos e na prática do terrorismo é rechaçada com indignação pelos que seguem na corrente da mentalidade predominante - ou seria se estas palavras pudessem ser ouvidas -, como se fora antissemitismo maldisfarçado.” (CHOMSKY, Noam. Op. cit., p. 58). Para uma rápida discussão sobre a desobediência civil como direito fundamental, cf. MATOS, Andityas Soares de Moura Costa. A desobediência civil como direito fundamental. Revista Del Rey Jurídica, ano 8, n. 16, Belo Horizonte: Del Rey, p. 56-58, jan./jun. de 2006. Algumas boas indicações de leitura sobre o tema podem ser encontradas em GARCIA, Maria. Desobediência civil: direito fundamental. 2. ed. rev., atual. e ampl. São Paulo: Revista dos Tribunais, 2004.

14 “As pessoas não conseguem perceber fatos elementares e jamais tiram conclusões óbvias. Verdades simples, quando expressas, provocam descrença, aversão ou indignação - pelo simples fato de serem enunciadas.” (CHOMSKY, Noam. Op. cit., p. 232)

15 Apud CHOMSKY, Noam. Op. cit., p. 69.

16 MARCUSE, Herbert. Op. cit., p. 28-29.

17 "Aqui, os controles sociais extorquem a necessidade irresistível para a produção e o consumo do desperdício; a necessidade de trabalho estupefaciente onde não mais existe necessidade real; a necessidade de modos de descanso que mitigam e prolongam essa estupefação; a necessidade de manter liberdades decepcionantes como as de livre competição a preços administrados, uma imprensa livre que se autocensura, a livre escolha entre marcas e engenhocas." (MARCUSE, Herbert. Op. cit., p. 28)

18 MARCUSE, Herbert. Op. cit., p. 30.

19 HUXLEY, Aldous. Op. cit., p. 186.

20 MARCUSE, Herbert. Op. cit., p. 23.

21 MARCUSE, Herbert. Op. cit., p. 24.

22 MARCUSE, Herbert. Op. cit., p. 23.

23 Para uma discussão calcada na matriz fenomenológico-existencial acerca das implicações da utopia na realidade contemporânea, cf. a excelente obra coletiva organizada por MARDER, Michael; VIEIRA, Patrícia (Orgs.). Existential utopia: new perspectives on utopian thought. London/New York: 2012. 
24 Pesquisa de datação realizada no Dicionário eletrônico Houaiss da língua portuguesa.

25 MORUS, Thomas. Utopia. Tradução Luís de Andrade. São Paulo: Abril Cultural, 1972 (Coleção "Os pensadores"). A primeira edição do livro data de 1516 e o seu título completo em latim é "Libellus vere aureus, nec minus salutaris quam festivus, de optimo rei publicae statu deque nova Insula Utopia”.

26 MANNHEIM, Karl. Ideologia e utopia. Tradução Sérgio Magalhães Santeiro. Rio de Janeiro: Zahar, 1968. A edição original é de 1929 .

27 MAFFEY, Aldo. Verbete “Utopia” (p. 1284-1290). In: BOBBIO, Norberto; GIANFRANCO, Pasquino; MATTEUCCI, Nicola (Orgs.). Dicionário de política. Tradução Carmem C. Varriale et all. Coordenação da tradução de João Ferreira. 5. ed. Brasília: UnB; São Paulo: Imprensa Oficial do Estado, 2000. 2 v., p. 1285-1286.

28 OST, François. Contar a lei: as fontes do imaginário jurídico. Tradução Paulo Neves. São Leopoldo: Unisinos, 2005, p. 373-382.

29 "It is, perhaps, too complimentary to call them Utopians, they ought rather to be called dys-topians, or caco-topians. What is commonly called Utopian is something too good to be practicable; but what they appear to favour is too bad to be practicable." (Oxford English Dictionary. Disponível em: http://www.oed.com/)

30 ORWELL, George. 1984. Tradução Wilson Velloso. 29. ed. São Paulo: Companhia Editora Nacional, 2005, p. 255.

31 Apud MAFFEY, Aldo. Op. cit., p. 1288.

32 "Estes homens regenerados considerar-se-ão livres, sem saber que foram obrigados a ser felizes, de uma felicidade imutável, porque ter-se-á perdido todo o impulso e toda a capacidade crítica.” (MAFFEY, Aldo. Op. cit., p. 1288)

33 PLATÃO. A república. Tradução introdução e notas Maria Helena da Rocha Pereira. 9. ed. Lisboa: Calouste Gulbenkian, 2001.

34 PLATÃO. Op. cit., p. 449-474.

35 Infelizmente, o texto da $A$ república de Zenão encontra-se irremediavelmente perdido. Apenas alguns fragmentos da obra sobreviveram aos séculos. As informações que alinhavamos foram compiladas por Diógenes Laércio no século III de nossa era e constam de seu famoso tratado Vida e opinião dos filósofos ilustres. Cf. DIOGĖNE LAËRCE. Vies et opinions des philosophes: livre VII. Tradução Émile Bréhier. Revisão Victor Goldschmidt e P. Kucharski. Rubriques. Notice et notes Victor Goldschmidt. In: SCHUHL, Pierre-Maxime (Ed.). Les stö̈ciens. Bibliothèque de la Pléiade. Paris: Gallimard, 2002, VII, 32-33, p. 27-28. Para uma leitura contemporânea do que chegou até nós da $A$ república de Zenão, cf. SCHOFIELD, Malcom. The stoic idea of the city. Chicago: The University of Chicago Press, 1999.

36 SADE, Marquês de. A filosofia na alcova. Tradução Augusto Contador Borges. São Paulo: Iluminuras, 1999.

37 O vocábulo dystopia encontra-se particularmente bem desenvolvido na Wikipédia de língua inglesa, contando inclusive com ricas listas das principais obras distópicas do século XX nos quadrinhos, na literatura, no cinema, na música, na televisão e nos videogames. Disponível em: <http://en.wikipedia.org/wiki/Dystopia>. Acesso em: 29 dez. 2007.

38 Apud MAFFEY, op. cit., p. 1289.

39 O mais ambicioso dos romances de Orwell foi escrito em 1948 e publicado em 1949, já tendo sido adaptado três vezes para a televisão e duas vezes para o cinema: em 1956, com direção de Michael Anderson, e em 1984, dirigido por Michael Radford. Planeja-se uma nova versão cinematográfica com direção de Tim Robbins. O título original do romance é Nineteen eighty-four e as referências relativas à sua edição brasileira encontram-se na nota de rodapé n. 30. A popularidade e a influência do livro foram enormes na cultura pop do século XX. Seus descendentes mais conhecidos foram o filme Brazil (o seu título original deveria ser 1984 1/2), de 1985, dirigido por Terry Gilliam, película que mostra o nosso país controlado por uma burocracia similar a que serve ao Grande Irmão, a novela 1985, de Anthony Burgess, que, mais do que uma sequência de 1984, constitui uma homenagem a Orwell, e a graphic novel intitulada $V$ for vendetta, de Allan Moore, que retrata uma Inglaterra fascista da qual foram extirpados os homossexuais, os árabes e os negros. 
40 Brave new world foi escrito em 1932 e traduzido desde então para as principais línguas do planeta. Trata-se, certamente, da mais influente distopia moderna, encontrando rival digna apenas em 1984. Eis as referências da edição brasileira: HUXLEY, Aldous. Admirável mundo novo. Tradução Vidal de Oliveira e Lino Vallandro. Porto Alegre: Globo, 1980. O enredo do livro se passa na cidade de Londres do ano de 2540 (ano de Ford 632). O que restou da civilização é governado de maneira totalitária por uma elite de cientistas. O livro discute questões éticas relativas ao avanço da engenharia genética e da biotecnologia, refletindo ainda sobre a possibilidade de controle da população por meio de drogas fornecidas pelo governo. Em 1958, Huxley lançou Brave new world revisited, texto não fictício em que analisa a situação mundial então existente para concluir que estamos cada vez mais próximos do futuro distópico por ele idealizado: superpopuloso, submergido no consumo de drogas e no qual a obediência das massas se funda em várias formas de controle subliminar. As referências da edição brasileira encontram-se na nota de rodapé n. 1.

41 A clockwork orange foi publicado em 1962 e filmado por Stanley Kubrick em 1971. A obra é ambientada na Inglaterra do ano de 2017 e narra em primeira pessoa as aventuras e desventuras de Alex, um jovem sociopata de 15 anos que, após ser preso, é submetido a um programa de reabilitação governamental chamado Ludovico technique. Tal programa - na verdade, uma terapia do tipo pavloviana - consiste na exposição prolongada de criminosos a imagens de extrema violência, ao mesmo tempo em que ingerem drogas que causam fortes náuseas. Ao final do tratamento, Alex se torna incapaz de vislumbrar quaisquer atos de violência ou de sexo, além de desenvolver aversão à sua antes adorada música clássica, dado que um dos filmes apresentados durante o processo incluía como trilha sonora a Ode à alegria da nona sinfonia de Beethoven. Referências da edição brasileira: BURGESS, Anthony. Laranja mecânica. Tradução Fábio Fernandes. São Paulo: Aleph, 2004.

42 A scanner darkly foi escrito em 1977 e retrata a futurística Califórnia de 1994. Na visão apocalíptica de Dick, os EUA perderam a guerra contra as drogas e padecem de uma epidemia causada pelo uso intensivo da substância D, que lentamente dissolve a personalidade e a inteligência dos seus usuários. Os principais temas abordados referem-se à problemática da personalidade individual e ao controle governamental da vida privada, assunto já clássico nas distopias do século XX. A obra foi adaptada em 2006 para o cinema pelo badalado diretor cult Richard Linklater, que produziu uma espécie de desenho animado extremamente refinado utilizando a técnica da rotoscopia, na qual os frames do filme servem de base para a animação. Aliás, muitos dos romances de Philip Dick se transformaram em filmes de sucesso, tal como Androids dream of electric sheep, de 1968, que passou em 1982 para as telas sob direção de Ridley Scott e com o título de Blade runner. A scanner darkly, livro e filme, foram lançados no Brasil com um título de duvidosa adequação: O homem duplo (DICK, Philip K. O homem duplo. Tradução Ryta Vinagre. São Paulo: Rocco, 2007).

43 ORWELL, George. Op. cit., p. 299-300.

44 Fahrenheit 451 é um romance de ficção científica publicado em 1953 por um dos maiores mestres do gênero: Ray Bradbury (edição brasileira: BRADBURY, Ray. Fahrenheit 451. Tradução Cid Knipel. São Paulo: Globo, 2003). A obra retrata uma futura América hedonista e antissocial, dominada pela televisão e onde os livros são proibidos, assim como todo e qualquer pensamento crítico. O personagem principal, Guy Montag, é um bombeiro que se rebela contra o sistema e passa a guardar e a ler os livros que deveria queimar. O curioso título da novela refere-se à temperatura em que o papel utilizado para a impressão de livros entra em combustão. O final da trama constituiu um dos pontos altos da história, tendo sido retratado com grande lirismo pelo diretor francês François Truffaut na sua versão cinematográfica de 1966. Planeja-se um novo filme dirigido por Frank Darabont, para quem a obra de Bradbury é hoje, nos EUA do fim do século XX e início do XXI, mais atual do que nunca.

45 O trecho é delicioso e merece transcrição: "Certo dia, Ulrich deixou de querer ser uma esperança. Naquela época já se começava a falar de gênios do futebol ou do boxe, mas para no mínimo dez inventores, tenores ou escritores geniais, os jornais não citavam mais do que, no máximo, um centro-médio genial, ou um grande tático de tênis. A nova mentalidade ainda não estava muito segura de si. Mas foi exatamente aí que Ulrich leu em alguma parte, como antecipação de verão, a expressão 'cavalo de corrida genial'. Era uma notícia sobre um grande sucesso nas pistas de corrida, e o autor talvez nem tivesse consciência de toda a dimensão da sua idéia, que o espírito dos tempos lhe inspirara” (MUSIL, Robert. O homem sem qualidades. Tradução Lya Luft e Carlos Abbenseth. Rio de Janeiro: Nova Fronteira, 2006, p. 63).

46 SALGADO, Joaquim Carlos. A ideia de justiça no mundo contemporâneo: fundamentação e aplicação do direito como maximum ético. Belo Horizonte: Del Rey, 2006.

47 BOBBIO, Norberto. A era dos direitos. Tradução Carlos Nelson Coutinho. Rio de Janeiro: Campus, 1992. 


\section{REFERÊNCIAS BIBLIOGRÁFICAS}

BINDER, Guyora; WEISBERG, Robert. Literary criticisms of law. New Jersey: Princeton University, 2000. BOBBIO, Norberto. A era dos direitos. Tradução Carlos Nelson Coutinho. Rio de Janeiro: Campus, 1992. O positivismo jurídico: lições de filosofia do direito. Tradução Márcio Pugliesi, Edson Bini e Carlos E. Rodrigues. São Paulo: Ícone, 1999. BRADBURY, Ray. Fahrenheit 451. Tradução Cid Knipel. São Paulo: Globo, 2003. BURGESS, Anthony. Laranja mecânica. Tradução Fábio Fernandes. São Paulo: Aleph, 2004. CHOMSKY, Noam. Piratas \& imperadores, antigos \& modernos: o terrorismo internacional no mundo real. Tradução Milton Chaves de Almeida. Rio de Janeiro: Bertrand Brasil, 2006.

CORPUS IURIS CIVILIS. Ed. Th. Mommsen/P. Krüger, Berlin, 1954. Versio digitalis: Alexandr Koptev. Bibliotheca Augustana. Disponível em: <http://www.hs-

augsburg. de/ Harsch/Chronologia/Lspost06/Iustinianus/ius_intr.html>. Acesso em: 9 abr. 2008.

DICK, Philip K. O homem duplo. Tradução Ryta Vinagre. São Paulo: Rocco, 2007.

DIMOULIS, Dimitri. Positivismo jurídico: introdução a uma teoria do direito e defesa do pragmatismo jurídicopolítico. São Paulo: Método, 2006.

DIOGĖNE LAËRCE. Vies et opinions des philosophes. Tradução Émile Bréhier. Rev. Victor Goldschmidt et P. Kucharski. Rubriques, notice et notes Victor Goldschmidt. In: SCHUHL, Pierre-Maxime (Ed.). Les stö̈ciens. Bibliothèque de la Pléiade. Paris: Gallimard, 2002.

GARCIA, Maria. Desobediência civil: direito fundamental. 2. ed. rev., atual. e ampl. São Paulo: Revista dos Tribunais, 2004.

GODOY, Arnaldo Sampaio de Moraes. Direito \& literatura: anatomia de um desencanto. Curitiba: Juruá, 2002. Direito e literatura. Os pais fundadores: John Henry Wigmore, Benjamin Nathan Cardozo e Lon Fuller. BuscaLegis.ccj.ufsc.br. Acesso em: 9 nov. 2012.

HOERSTER, Norbert. En defensa del positivismo jurídico. Tradução Ernesto Garzón Valdés. Barcelona: Gedisa, 2000. HOUAISS, Antônio. Dicionário eletrônico Houaiss da língua portuguesa. Versão 1.0. Dezembro de 2001.

HUXLEY, Aldous. Admirável mundo novo. Tradução Vidal de Oliveira e Lino Vallandro. Porto Alegre: Globo, 1980. Regresso ao admirável mundo novo. Tradução Eduardo Nunes Fonseca. Belo Horizonte/Rio de

Janeiro: Itatiaia, 2000.

KELSEN, Hans. Das Problem der Souveränität und die Theorie des Völkerrechts. Tubingen: Mohr, 1920. Teoria geral das normas. Tradução e estudo introdutório José Florentino Duarte. Porto Alegre: Sergio Antonio Fabris, 1986.

Teoria geral do direito e do estado. Tradução Luís Carlos Borges. 3. ed. São Paulo: Martins Fontes, 2000. Théorie pure du droit. Adaptée de l'allemand par Henri Thévenaz. 2. ed. Neuchâtel: Éditions de la Baconnière, 1988.

MAFFEY, Aldo. Verbete “Utopia”. In: BOBBIO, Norberto; GIANFRANCO, Pasquino. MATTEUCCI, Nicola (Orgs.). Dicionário de política. Trad. Carmem C. Varriale et all; Coordenação da tradução de João Ferreira. 5. ed. Brasília: UnB; São Paulo: Imprensa Oficial do Estado, pp. 1284-1290, 2000. 2 v.

MANNHEIM, Karl. Ideologia e utopia. Tradução Sérgio Magalhães Santeiro. Rio de Janeiro: Zahar, 1968. MARCUSE, Herbert. A ideologia da sociedade industrial: o homem unidimensional. Tradução Giasone Rebuá. 6. ed. Rio de Janeiro: Zahar, 1982.

MARDER, Michael; VIEIRA, Patrícia (Orgs.). Existential utopia: new perspectives on utopian thought. London/New York: 2012.

MATOS, Andityas Soares de Moura Costa. Direito: perguntas e respostas. Questões teóricas, acadêmicas e ético-profissionais. Belo Horizonte: Del Rey, 2007.

A desobediência civil como direito fundamental. Revista Del Rey Jurídica, ano 8, n. 16, Belo

Horizonte: Del Rey, p. 56-58, jan./jun. de 2006.

MORAWETZ, Thomas. Law and literature. In: PATTERSON, Dennis (Org.). A companion to philosophy of legal and legal theory. Malden: Blackwell, 1996.

MORUS, Thomas. Utopia. Tradução Luís de Andrade. São Paulo: Abril Cultural, 1972 (Coleção "Os pensadores”). MUSIL, Robert. O homem sem qualidades. Tradução Lya Luft e Carlos Abbenseth. Rio de Janeiro: Nova Fronteira, 2006.

ORWELL, George. 1984. Tradução Wilson Velloso. 29. ed. São Paulo: Companhia Editora Nacional, 2005. OST, François. Contar a lei: as fontes do imaginário jurídico. Tradução Paulo Neves. São Leopoldo: Unisinos, 2005. PLATÃO. A república. Tradução introdução e notas Maria Helena da Rocha Pereira. 9. ed. Lisboa: Calouste Gulbenkian, 2001.

SADE, Marquês de. A filosofia na alcova. Tradução Augusto Contador Borges. São Paulo: Iluminuras, 1999. 
SALGADO, Joaquim Carlos. A ideia de justiça no mundo contemporâneo: fundamentação e aplicação do direito como maximum ético. Belo Horizonte: Del Rey, 2006.

SCHOFIELD, Malcom. The stoic idea of the city. Chicago: The University of Chicago Press, 1999.

SÉNECA, Lucio Anneo. Cartas a Lucilio. Tradução prólogo e notas Vicente López Soto. 3. ed. Barcelona:

Juventud, 2006

$$
\begin{array}{r}
\text { Faculdade de Direito da UFMG } \\
\text { Av. João Pinheiro, n. } 100 \\
\text { Centro }-30130-180 \\
\text { Belo Horizonte - MG - Brasil } \\
\text { andityaslaufmg.br }
\end{array}
$$

\section{Andityas Soares de Moura Costa Matos}

Graduado em Direito, Mestre em Filosofia do Direito e Doutor em Direito e Justiça pela Faculdade de Direito da Universidade Federal de Minas Gerais (UFMG)

Professor Adunto de Filosofia do Direito e disciplinas afins na Faculdade de Direito da UFMG

Professor Titular de Filosofia do Direito no curso de Graduação em Direito da FEAd (Belo Horizonte/MG) 
366 : DIREITO, TÉCNICA E DISTOPIA: UMA LEITURA CRÍTICA 
